\title{
Preparation of Fine-Grained Silicon-Nitride Ceramics and their Characterization by Depth-Sensing Indentation Tests
}

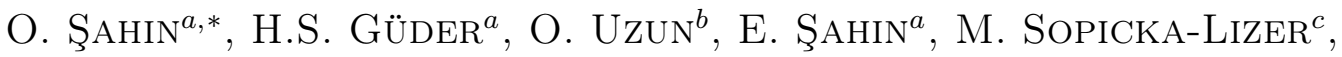 \\ H. GÖÇMEZ ${ }^{d}$ AND E. ARTunC ${ }^{e}$ \\ ${ }^{a}$ Mustafa Kemal University, Department of Physics, Micro/Nanomechanic Characterization Laboratory, \\ Hatay, Turkey \\ ${ }^{b}$ Bülent Ecevit University, Faculty of Engineering, Zonguldak, Turkey \\ ${ }^{c}$ Silesian University of Technology Department of Materials Science, Katowice, Poland \\ ${ }^{d}$ Dumlupınar University Department of Ceramic Engineering, Kütahya, Turkey \\ ${ }^{e}$ Süleyman Demirel University, Department of Physics, Isparta, Turkey
}

\begin{abstract}
Both pressureless-sintered and dense, fine-grained silicon nitride ceramics were produced from mechanochemically activated nitride-based precursors. Scanning Electron Microscopy (SEM), Transmition Electron Microscopy (TEM), X-Ray Diffraction (XRD) and an ultra-low load microhardness tester were used to characterize these ceramics. Depth-sensing indentation (DSI) tests in the range of $200-1800 \mathrm{mN}$ were performed on the silicon nitride ceramic to determine dynamic hardness $\left(H_{d}\right)$ and reduced elastic modulus $\left(E_{r}\right)$ values. These values were deduced by analyzing the unloading segments of the DSI curves. It was found that both $H_{d}$ and $E_{r}$ exhibits a significant indentation load dependence. Nix-Gao (NG) model was used to analyze the dynamic hardness data in the calculation of the load independent hardness value.
\end{abstract}

DOI: 10.12693/APhysPolA.128.B-355

PACS: $62.20 .-\mathrm{x}, 62.20 . \mathrm{de}, 81.05 . \mathrm{Je}$

\section{Introduction}

Silicon nitride ceramics have been studied for the last four decades due to their excellent thermo-mechanical properties. These properties are the result of their composite microstructure and creep resistance. Consequently, several works have been devoted the manufacturing of silicon nitride ceramics and to the investigation of their microstructure-related properties [1-5]. Recently, nano-ceramic materials with expected increase in hardness, wear resistance and super plasticity have been reported [6-9]. These improved properties can be achieved by nano-powders $[8]$ or by mechanochemical processing [9]. However, densification of samples requires high heating rates to suppress grain growth [6]. Pressurelesssintered silicon nitride ceramics from a mechanochemically processed precursor have been developed either as an economically, functionally superior alternative to hotpressed silicon nitride (HPSN) or as a substitute for the fine-grained ceramics obtained by spark plasma sintering technique.

Mechanochemically processed silicon nitride powders have high densification and compaction at relatively low temperatures [10-11]. However, the microstructure of silicon nitride sintered at low temperatures differs from the one produced by hot-pressing, because the grain growth is substantially suppressed in the former. Nevertheless,

*corresponding author; e-mail: osahin@mku.edu.tr new silicon nitride ceramics with limited grain growth, whose microstructure differs from the standard silicon nitride-based ceramics, are of interest for application purposes where both high hardness and good wear resistance are required. Therefore, it is necessary to investigate the microstructure-related mechanical properties of the new class of fine-grained silicon nitride ceramics.

Surface deformation by the depth-sensing indentation technique outside the indenter can be considered to be inelastic due to cracking. This cracking is typical for many ceramics. It affects the slopes of the loading and the unloading curves in different ways. The DSI technique allows to evaluating the elastic response in the micro-range after indention from the initial slope of the unloading curve. Therefore, depth-sensing indentation measurements are more appropriate than the traditional methods to study the characteristic indentation response of the fine-grained ceramics. The aim of this work is to investigate fine-grained silicon nitride ceramics fabricated from the mechanochemically processed precursor by the depth-sensing indentation technique at several peak loads ranging from 200 to $1800 \mathrm{mN}$, and to determine the indentation hardness and the reduced elastic modulus by the Oliver-Pharr (OP) model [12].

\section{Experimental procedure}

The initial batch of the precursor is consists of 89.3 wt.\% of $\beta-\mathrm{Si}_{3} \mathrm{~N}_{4}$ (Aldrich-325 mesh, containing traces of $\mathrm{Si}_{2} \mathrm{~N}_{2} \mathrm{O}$ and $4-5$ wt.\% of $\left.\alpha-\mathrm{Si}_{3} \mathrm{~N}_{4}\right), 5.7$ wt.\% of AlN (H.C. Starck-C) and 5 wt.\% of $\mathrm{Y}_{2} \mathrm{O}_{3}$ (H.C. Starckgrade $\mathrm{C}$ ). Alumina was eliminated from the batch 
composition as some oxidation during mechanochemical processing could occur. The mechanochemical processing of the batch was performed in an innovative MPP-1 planetary mill (TTD, Russia), in an argon atmosphere, with a ball-to-powder ratio $6: 1$, for 30 min acceleration of the centrifugal field of $50 \mathrm{~g}$ ( $\mathrm{g}$ is the gravitational acceleration). The resultant powder showed high specific surface area as determined by BET $\left(27.9 \mathrm{~m}^{2} / \mathrm{g}\right.$, ASAP 2010), significant crystal lattice damage, as confirmed by XRD (X'PERT), and increased oxygen content (5.8 wt.\%, ELTRA ON). Both the Si:Al ratio as well as the measured content of oxygen were sufficient to produce a $\beta$-sialon solid solution with a $\mathrm{z}$ value of 0.3 . The mechanochemically processed powder was uniaxially pressed into the form of tablets with $20 \mathrm{~mm}$ diameter and between 5 and $6 \mathrm{~mm}$ height. Subsequently, it was cold isostaticaly and pressed at $250 \mathrm{MPa}$. The pressed tablets were contained within a powder bed of $\mathrm{Si}_{3} \mathrm{~N}_{4} / \mathrm{BN}$ in a $\mathrm{BN}$ crucible with a lid. Densification was carried out in a graphite furnace (Thermal Technology) at $1600^{\circ} \mathrm{C}$ for 1 hour under nitrogen flow. Density was determined in distilled water by the Archimedes technique. XRD measurements were performed with both $\mathrm{Cu} K_{\alpha}$ radiation and an incident beam monochromator (X'pert, Philips-Panalytical) on the polished cross section of the tablets. Rietveld refinement was used for calculation of the unit cell parameters. Z-value of the resultant $\beta$-sialon solid solution was determined from the unit cell parameters according to the Ekström formula [13].

Thin foils for the transmission observations were cut with a $\mathrm{Ga}+$ focused ion beam (FIB) technique. The microstructure studies were completed using a TECNAI G ${ }^{2}$ FEG $20(200 \mathrm{kV})$ equipped with an EDAX integrated XRay energy dispersive spectroscopy (EDS) microanalysis system. The scanning-transmission images were acquired using an HAADF detector.

Hardness measurements were performed on the polished cross section of the tablet using a dynamic ultra microhardness tester (Shimadzu, DUH-W201S) with Vickers indenter attached to its tip. This tester had a maximum penetration depth upto10 $\mathrm{mm}$ and indenter shift resolution of $1 \mathrm{~nm}$ at room temperature. A load cell and displacement-voltage dilatometer (LVDT) was used both to control the applied load and to measure the penetration depth of the indenter. The maximum load for an easier interpretation of mechanical behavior at various depth was changed at regular intervals, such as $200-1800 \mathrm{mN}$, under a loading/unloading rate of $14.126 \mathrm{mN} / \mathrm{s}$. At least five indentation tests were conducted on a sample surface to increase reliability of the experimental results. The benefit of simultaneously measuring the loads and the penetration depth during indentation is that both the indentation hardness and reduced elastic modulus, as determined by the OP method [12]. The hardness is given by:

$$
H_{d}=\frac{P_{\max }}{A_{c}},
$$

where $P_{\max }$ and $A_{c}$ are denoted as the maximum indentation load and the projected contact area, respectively. Because the real contact area of the indenter generally deviated from the ideal relation under a small indentation depth because of the shape imperfection of the indenter tip, a precise correction function for the real contact area of the indenter tip was established in advance by calibration using a standard fused silica. On the other hand, the peak indentation test load-penetration depth behavior can be effectively used in defining a reduced elastic modulus $\left(E_{r}\right)$ through the equation:

$$
\frac{1}{E_{r}}=\frac{1-\nu_{s}^{2}}{E_{s}}+\frac{1-\nu_{i}^{2}}{E_{i}}
$$

where $\nu$ is the Poisson ratio, with the subscripts $s$ and $i$ indicating sample and indenter, respectively. $E_{r}$ value of the sample is given by:

$$
E_{r}=\frac{\sqrt{\pi}}{2} \frac{S}{\sqrt{A_{c}}},
$$

where $\mathrm{S}$ is the contact stiffness and $A_{c}$ is the projected contact area $\left(26.43 h_{c}^{2}\right)$ of the sample.

\section{Results and discussion}

Resultant ceramic specimens were characterized according to the mono-phase composition $\beta-\mathrm{Si}_{3} \mathrm{~N}_{4}$, (Fig. 1). However, the lattice parameters derived from Rietved refinement of XRD data revealed the formation of a solid solution ( $\beta$-sialon) with a $\mathrm{z}$ value of 0.3 . Density of the specimens was calculated to be $3.19 \pm 0.01 \mathrm{~g} \mathrm{~cm}^{-3}$. Assuming that the density of $\beta$-sialon $(z=0.3)$ is 3.188 as calculated from the XRD data and density of Y-Si-Al-O-N glass with high yttria content is close to $4.1 \mathrm{~g} \mathrm{~cm}^{-3}[14]$. We could estimate the relative density of the resultant specimens approaches to $99 \%$. The specimen fracture surface observed in SEM (Fig. 2a) indicates well-crystallized grains with both a low aspect ratio and diameter well below $1 \mu \mathrm{m}$.

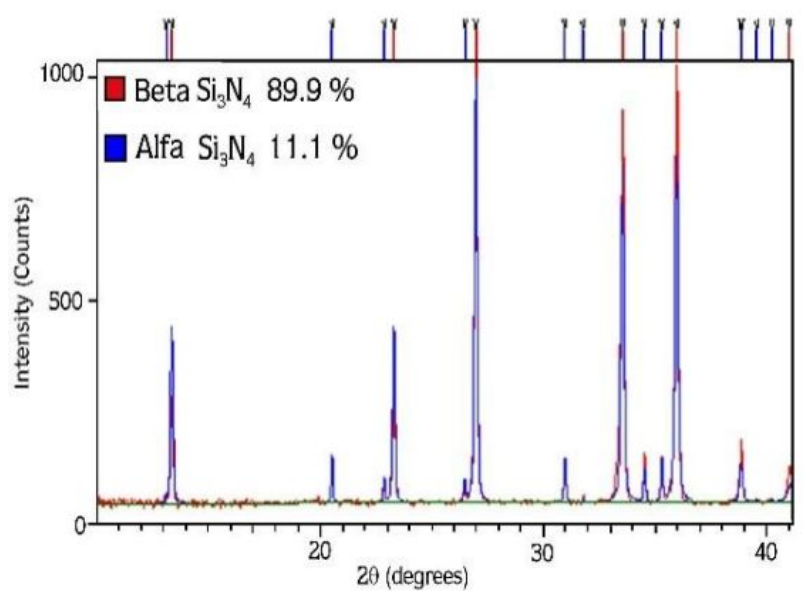

Fig. 1. XRD pattern of sintered material. 

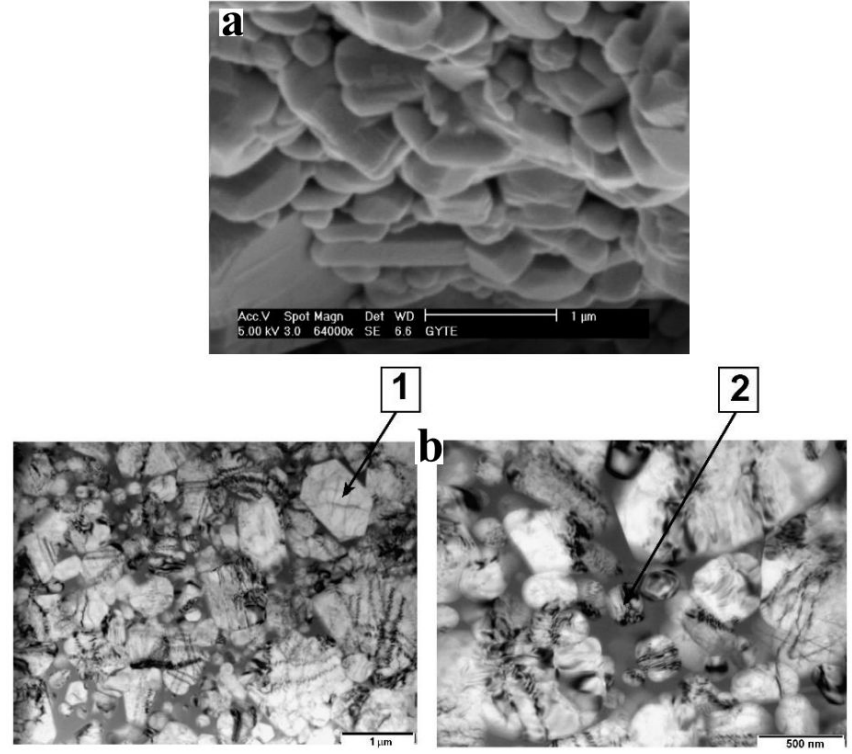

Fig. 2. SEM micrograph of the silicon nitride fractured surface. (b) TEM micrographs; showing greater $\beta$ sialon grains and smaller $\alpha-\mathrm{Si}_{3} \mathrm{~N}_{4}$ crystals; 1 - basal plane of $\beta$-sialon crystal; $2-$ one of $\alpha-\mathrm{Si}_{3} \mathrm{~N}_{4}$ crystals.

Typical applied test load-penetration depth curves as a function of the indentation load during DSI tests are shown in Fig. 3. This figure indicates nine different loadunload indentation cycle tests and elastoplastic behavior at room temperature for the sample. The loading segments of curves interlink with each other, indicating a similar deformation mechanism for the nine cycles of each indentation experiment. The distance between unloading curves decreases, however, with increasing applied test loads. The area of resulting hysteresis loops is a measure of the energy dissipation of irreversible processes occurred during loading-unloading. Such a specimen response is closely related to its microstructure as shown in Fig. 2b. Two populations of grains exist: larger well-crystallized $\beta$-sialon grains with diameter up to $1 \mu \mathrm{m}$ and smaller grains below $200 \mathrm{~nm}$ with rounded edges of $\alpha$ $\mathrm{Si}_{3} \mathrm{~N}_{4}$, as detected by EDS studies. The former originates from mechanochemically deformed primary particles of $\beta$-Si ${ }_{3} \mathrm{~N}_{4}$ after densification and moderate grain growth. The latter are residuals of the primary $\alpha-\mathrm{Si}_{3} \mathrm{~N}_{4}$ particles before they were dissolved in the Y-Si-Al-O-N liquid. Consequently, the smaller $\alpha-\mathrm{Si}_{3} \mathrm{~N}_{4}$ grains are embedded in the surrounding Y-Si-Al-O-N glass with much smaller elastic modulus in comparison to the $\beta$-sialon grains.

The observed ultrasonic wave velocity anisotropy suggests preferred orientation of elongated $\beta$-sialon grains mostly at the small angle to the direction of the applied load i.e. the $\beta$-sialon grains with the basal plane (0001) parallel to the sample surface (Fig. 2b). Because the penetration depth of the smallest applied load $(0.8 \mu \mathrm{m})$ is within the range of the $\beta$-sialon crystals size, the resultant material response must be related to both the elastic-plastic deformation of the individual $\beta$-sialon

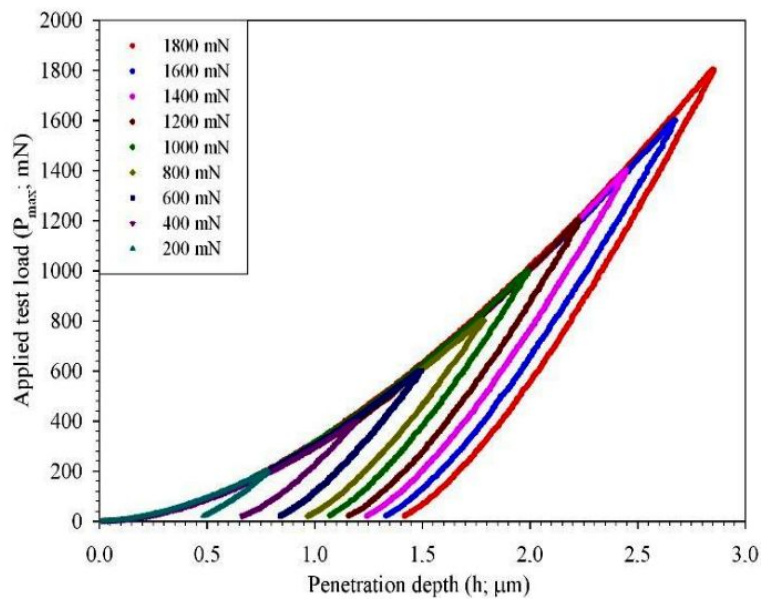

Fig. 3. Applied test load-penetration depth curves of tested ceramic.

grain itself and the surrounding glassy phase. Over the given value of the applied load, the effect of the glassy phase in the specimen response becomes less dominant in the specimen response due to its limited amount.

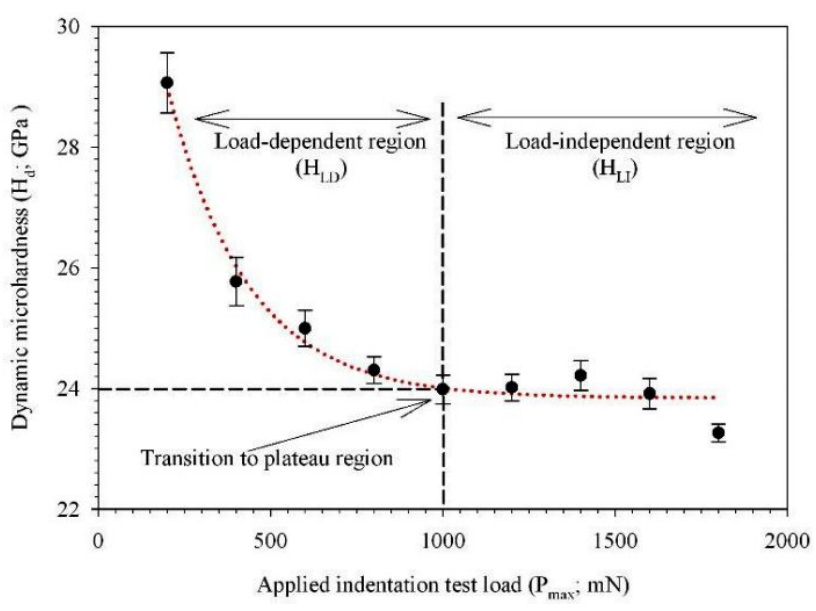

Fig. 4. Variation of the dynamic microhardness with the applied indentation test load.

DSI values at each imposed depth $\left(H_{d}\right)$ were calculated using Eq. (1). The peak indentation test load dependence of the dynamic hardness data is obtained from the examined material and is displayed in Fig. 4. The dynamic hardness values decrease with increase in the applied indentation test load. The apparent $H_{d}$ is a function of the applied load at low peak indentation test loads where there is no constant value for the hardness ( $H_{L D}$; load-dependent hardness). At high-applied indentation test loads, the hardness is constant with respect to the indentation test load and a single, well-defined hardness value exists $\left(H_{L I}\right.$; load-independent hardness also known as the true hardness). This behavior is known as indentation size effect (ISE) [15].Similar results have been obtained for the porous SiAlON ceramics [16] as the individual $\beta$-sialon grains could deform elastically at low loads in the porous environment. Furthermore, the latest 
results show ISE for both basal and prismatic planes of $\beta$-Si ${ }_{3} \mathrm{~N}_{4}$ individual crystals in the polycrystalline ceramic [17]. The ISE has been examined extensively for different kinds of materials. In this study, The NG model is presented in the next section and it is applied to analyze the DSI data of fine grained silicon-nitride ceramics.

\subsection{NG model and present data}

Nix and Gao [18] developed a mechanism based on strain gradient (MSG) model to explain the indentation size effect. The MSG theory assumes that the indentation is accommodated by circular loops of geometrically necessary dislocations (GNDs) with Burgers vectors normal to the plane surface. The model combines the Taylor relation [19], the Mises flow rule, and the Tabor relation [20] to obtain the following characteristic expression for the depth dependence of hardness:

$$
\frac{H}{H_{0}}=\sqrt{1+\frac{h^{*}}{h}} .
$$

Variable $H$ is the nominal hardness for a given depth; both $h$ and $h^{*}$ are characteristic depths which depend on both the shape of the indenter and the material. Finally, $H_{0}$ can be defined as the hardness arising from the storing the statistically dislocations alone/equivalently. The hardness is obtained in the limit for an infinite depth (size independent hardness).

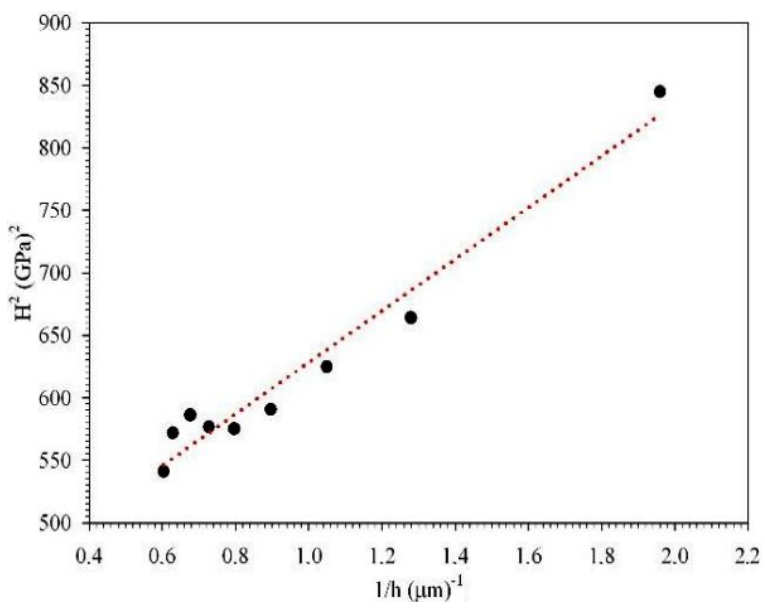

Fig. 5. The relationship between $H^{2}$ and $1 / h$ of ceramic sample.

In Fig. 5, the square of the dynamic hardness obtained in the indentation tests is plotted as a function of the reciprocal of the indentation depth. As can be seen from Fig. 5, a linear relationship exists between $H^{2}$ and $1 / h$, in agreement with Eq. (4). This relationship indicates that the dynamic hardness decreases due to the indentation size effect. From Fig. 5, the value of both $H_{0}$ and $h^{*}\left(h^{*}=0.489\right)$ can easily be determined from the intersection point and the slope of the curve, respectively. The data can then be displayed as a plot of $\left(H / H_{0}\right)^{2}$ vs $1 / h$, as shown for the silicon nitride sample in Fig. 6. It is almost linear and also consistent well with reference [18]. The NG model was used to determine the size

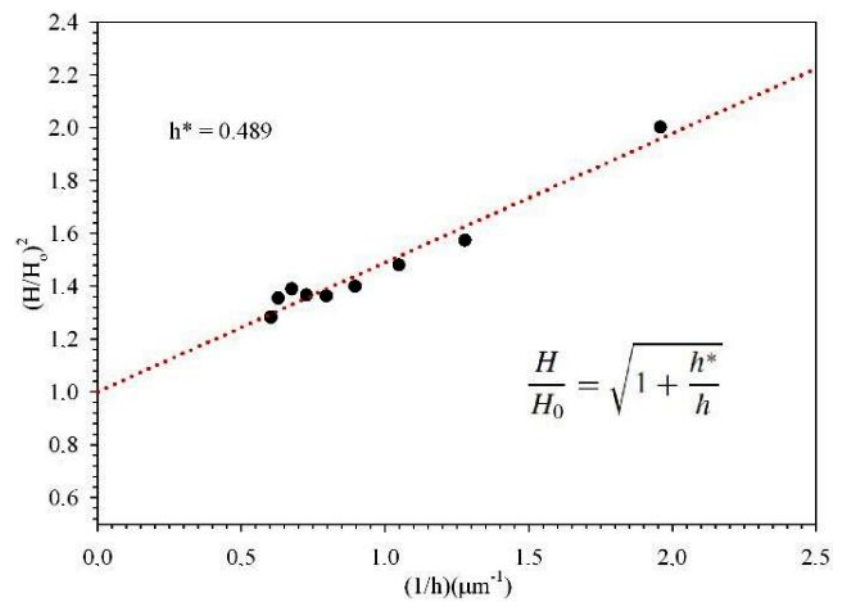

Fig. 6. Application of NG model to ceramic sample.

independent (load-independent) dynamic hardness values, $H_{N G}$, of the silicon nitride sample. The obtained value was $20.550 \mathrm{GPa}$. The Nix and Gao derived $H_{N G}$ value which is in good agreement with the microhardness of the $\beta-\mathrm{Si}_{3} \mathrm{~N}_{4}$ crystals measured at basal plane inside the polycrystalline gas pressure sintered silicon nitride ceramics $\left(2117 \pm 145 \mathrm{~kg} \mathrm{~mm}^{-2}\right)$ [21].

On the contrary, reduced elastic modulus $E_{r}$ is obtained from the analysis of the unloading curves using the Oliver and Pharr method. Eq. (3) can be rearranged as:

$$
S=\frac{2}{\sqrt{\pi}} \sqrt{26.43} h_{c} E_{r} .
$$

Eq. (5) is the basic equation for determination of reduced elastic modulus by DSI technique. The key quantities in this equation are the initial unloading contact stiffness, $S=\mathrm{d} P / \mathrm{d} h$ (i.e., the slope of the initial portion of the unloading curve) and the real contact depth, $h_{c}$ in order to determine $E_{r}$. Using the experimentally determined $S$ and $h_{c}$, the reduced elastic modulus by indentation was calculated. The results are illustrated in Fig. 7. The extracted reduced elastic modulus also exhibits a strong peak-load dependency. Therefore, the reduced elastic modulus can not be extracted from the peak indentation test load-penetration depth curve in terms of only one peak load.

As seen from Eq. (5), there is a linear relationship between initial unloading stiffness $(S)$ and the contact depth at peak load $\left(h_{c}\right)$ Hence, the reduced elastic modulus can be obtained directly from the slope of the best-fit lines for the silicon nitride ceramic. In Fig. 8, the experimentally determined $S$ is plotted as a function of the contact depth at peak load $\left(h_{c}\right)$ A good linearity between these two quantities for the examined material is clearly seen from the figure. The correlation coefficient obtained from the linear regression analysis is 0.976 . The loadindependent elastic modulus is obtained from the slope of the best-fit line in Fig. 8. The calculated $\left(E_{r}\right)$ value is $116.856 \mathrm{GPa}$. This value is in the load-independent elastic modulus area, shown in Fig. 7. 


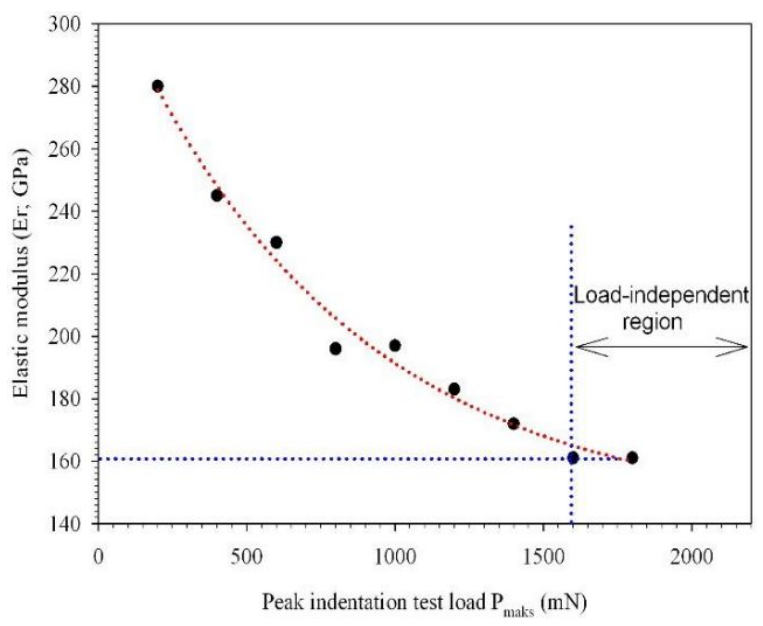

Fig. 7. Elastic modulus extracted from the analysis of the peak indentation test load penetration depth curves as a function of the peak loads for the tested sample.

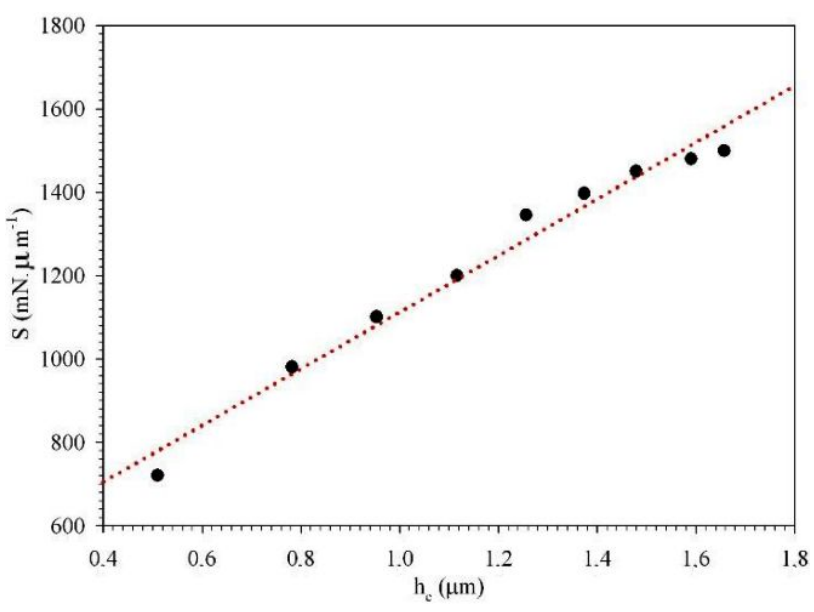

Fig. 8. Variation of initial unloading stiffness with the contact depth at peak load for silicon nitride ceramic.

\section{Conclusion}

Both pressureless-sintered and dense, fine-grained silicon nitride ceramics were produced from the mechanochemical activated nitride-based precursors. DSI tests are used to determine mechanical properties of the ceramics. Both the dynamic hardness and the reduced elastic modulus of fine-grained silicon nitride sample are load-dependent. The calculated value of loadindependent hardness using NG model was 20.550 GPa. The load-independent reduced elastic modulus $\left(E_{r}\right)$ also exhibits a peak-load dependency. Thus, we determined load independent modulus using the slope of the best-fit straight line between initial unloading stiffness, $S$, and the contact depth at peak load, $h_{c}$. The obtained value is $116.8 \mathrm{GPa}$.

\section{Acknowledgments}

The authors would like to acknowledge the financial support (Project no.: 2003K120510 and Project no.: 2010K121220) by Turkish State Planning Organization (DPT). The financial support from research foundation of Mustafa Kemal University (Grant No.: 12880 and 12364) is also gratefully acknowledged.

\section{References}

[1] S. Hampshire, J. Achiev, Mater. Manuf. Eng. 24, 43 (2007).

[2] P.F. Becher, G.S. Painter, N. Shibata, R.L. Satet, M.J. Hoffmann, S.J. Pennycook, Mat. Sci. Eng. A 422, 85 (2006).

[3] G. Petzow, M. Herrmann, Silicon nitride ceramics, Springer-Verlag, Berlin Heidelberg 2002.

[4] F.L Riley, J. Am. Ceram. Soc. 83, 245 (2000).

[5] A. Rosenflanz, Curr. Opin. Solid State Mat. Sci. 4, 453 (1999).

[6] A. Bellosi, J. Vicens, V. Medri, S. Guicciardi, Appl. Phys. A 81, 1045 (2005).

[7] T. Nishimura, X. Xu, K. Kimoto, N. Hirosaki, H. Tanaka, Sci. Technol. Adv. Mat. 8, 635 (2007).

[8] F.I. Bulić, I. Zalite, N. Zhilinska, J. Eur. Ceram. Soc. 24, 3303 (2004).

[9] X. Xu, T. Nishimura, N. Hirosaki, R.J. Xie, Y. Yamamoto, H. Tanaka, Nanotechnology 16, 1569 (2005).

[10] M. Sopicka-Lizer, M. Tańcula, T. Włodek, K. Rodak, M. Hüller, V. Kochnev, E. Fokina, J. Eur. Ceram. Soc. 28, 279 (2008).

[11] M. Sopicka-Lizer, C. Duran, H. Gocmez, T. Pawlik, M. Mikuskiewicz, K. MacKenzie, Ceramic International 39, 4269 (2013).

[12] W.C. Oliver, G.M. Pharr, J. Mater. Res. 7, 1564 (1992).

[13] T. Ekström, P.O. Käll, M. Nygren, P.O. Olsson, J. Mat. Sci. 24, 1853 (1989).

[14] H. Lemercier, T. Rouxel, D. Fargeot, J.-L. Besson, B. Pirious, J. Non-Cryst. Sol. 201, 128 (1996).

[15] J. Gong, J. Wu, Z. Guan, J. Eur. Ceram. Soc. 19 , 2625 (1999).

[16] O. Şahin, Chin. Phys. Lett. 24, 3206 (2007).

[17] E. Csehova, A. Duszova, P. Hvisdos, F. Lofaj, J. Dusza, P. Sajgalik, Chemické Listy 105, 783 (2011).

[18] W.D. Nix, H. Gao, J. Mech. Phys. Solids 46, 411 (1998).

[19] M.F. Ashby, Phil. Mag. 21, 399 (1970).

[20] D. Tabor, The hardness of metals, Clarendon Press, Oxford 1951.

[21] J. Dusza, T. Eschner, K.J. Rundgren, Mat. Sci. 16, 1664 (1997). 